\title{
Investigation of a Novel 3D Non-Destructive Evaluation for Corrosion Process in Reinforced Concrete
}

\author{
Guohao Fang, Biqin Dong, Ningxu Han, and Feng Xing \\ Department of Civil Engineering, Shenzhen University
}

\begin{abstract}
X-ray computed microtomography (X-ray $\mu \mathrm{CT}$ ) method is proposed to trace the corrosion features of steel bar in cementitious materials (e.g., concrete). Three-dimensional corrosion morphology (including morphology of steel corrosion, corrosion products, and cracks formation) are characterized and reconstructed. Experimental results demonstrate that X-ray $\mu \mathrm{CT}$ can track time-dependent development of corrosion products and the subsequent initiation and propagation of corrosion-induced cracks. In addition, scanning electron microscope (SEM) and energy dispersive spectrometer (EDS) are used to morphologically and chemically analyze the corrosion result. The microscopic analysis result is found to be in a very good agreement with the image analysis measured by $\mathrm{X}$-ray $\mu \mathrm{CT}$. Furthermore, the total corrosion ratio of steel, obtained by the $\mathrm{X}$-ray $\mu \mathrm{CT}$, is calculated to be in a good correlation with the data measured by Faraday's law as well as gravimetric method.
\end{abstract}

\section{INTRODUCTION}

Corrosion of reinforcement in reinforced concrete is a major deterioration problem causing considerable costs due to durability design, maintenance, and repair needs. In order to conquer this problem, however, it requires crucial information about the real corrosion process, such as at what point do corrosion products begin accumulating at the steel/concrete interface and eventually leading to corrosion-induced cracking of the surrounding concrete.

To address these problems, up to now, many different techniques are applied to investigate the steel corrosion in concrete. For corrosion monitor, electrochemical method is the main technique applying to monitor the corrosion process. But only indirect statistic information can be provided by these methods. Besides the information about the type of corrosion, the extent and distribution of corrosion region cannot be obtained by using these electrochemical techniques. In the investigation of mechanism, most researches are based on indirect observation methods such as cutting open the samples after evidence of extensive corrosion and external observation of surface crack propagation. However, these techniques only can be applied to study the corrosion mechanism via an indirect way rather than a direct comprehensive mode, which is easily affected by some interference factors (e.g., testing environment, processing procedure, and human factors).

X-ray computed microtomography (X-ray $\mu \mathrm{CT}$ ), which is widely used in medicine and material science, seems a possible technique to provide a direct and quantitative study for steel corrosion within concrete.
X-ray $\mu \mathrm{CT}$ has been demonstrated in numerous applications in cementitious material field, such as pore structure characterization, sulfate attack, and diffusivity in cracks. The technique used in related investigation on steel corrosion allows for real-time in situ 3D characterization of following mechanisms: (1) time-dependable corrosion process of the steel reinforcement and (2) quantitative analysis of corrosion ratio at different corrosion stages. Furthermore, this technique provides a platform for real-time monitoring without interfering with the chemistry and the morphology of the embedded steel, and offers the possibility of $3 \mathrm{D}$ imaging for comprehensive analysis.

In this study, X-ray $\mu \mathrm{CT}$ system is applied to investigate the corrosion process of reinforced cement paste. Active corrosion is induced by galvanostatically corroding steel embedded in cement paste. Raw image data are obtained and analyzed after every test to monitor the whole corrosion process. Also, SEM and EDS are also used to morphologically and chemically analyze the corrosion result. Finally, the corrosion ratio are calculated by XCT results and predicted by the Faraday's law as well as measured by gravimetric method in order to study the differentiation between different methods.

\section{MATERIALS AND METHODS}

The fresh mixture is cast into molds (with dimensions of $\Phi 10 \mathrm{~mm} \times 10 \mathrm{~mm}$ ) with a carbon steel rod with diameter of $2 \mathrm{~mm}$ in the centre. After $24 \mathrm{~h}$, the specimens are de-molded and then cured at a relative humidity of $95 \pm 5 \%$ and temperature of $20 \pm 2^{\circ} \mathrm{C}$ for 
28 days. It has to be noted that rubberized fabric are used to prevent corrosion of external reinforcement during the testing procedure.

In this research, an accelerated corrosion technique (known as galvanostatic corrosion) is applied for experimental study. The basic concept of anodic corrosion is using an external power supply to form an electrochemical circuit. As the purpose of the research is to test whether the X-ray $\mu \mathrm{CT}$ is suitable for the steel corrosion monitor, the current intensity is set as $0.15 \mathrm{~A}$ in order to accelerate the corrosion procedure. In addition, five accelerated times are applied to monitor the corrosion procedure.

X-ray $\mu \mathrm{CT}$ (Xradia, XCT-400, USA) is applied to take the internal 2D images after every accelerated corrosion time. Based on the raw data measured by $\mathrm{X}$-ray $\mathrm{CT}$, the reconstruction of inner microstructure of different samples is studied by means of image analysis technique. The corrosion process is evaluated with the help of the reconstruction of its inner microstructures (including 2D slices, 3D digital image) and quantitative analysis. In addition, Scanning Electron Microscope (SEM) and Energy Dispersive $X$-ray Analysis (EDX) are applied to validate the result measured by X-ray CT. What more, the corrosion ratio are calculated by XCT results and predicted by the Faraday's law as well as measured by gravimetric method in order to study the differentiation between different methods.

\section{RESULTS AND DISCUSSION}

Initially, the reconstructed tomogram showed the round disk of the steel reinforcing bar reach a very close position of centre of the cement paste disk (Figure 1a). After the first galvanostatic corrosion, the corrosion process was initiated in the interfacial transition zone (ITZ) (Figure 1b). With steel corrosion proceeding, some tine radial crack formed and grew larger with the increase of corrosion time (Figures 1c and d). In the end, the cracks propagated outwards and reach the surface of the specimen cover (Figure 1e). These penetrating cracks provided paths for a quicker ingress of water, chloride ions, and oxygen to the steel bars. Thus, the whole corrosion process is further accelerated in the later galvanostatic corrosion. As shown in Figure 1, the location of corrosion pack varies with location of the cracks after specimen surface cracking. Mainly, it often locates near the inner end of the crack, and the corrosion further propagates around the steel near the inner ends of cracks.

As shown in Figure 2, all the 2D reconstructed slices are rendered in $3 \mathrm{D}$ to obtain insight in the evolution of embedded steel throughout the cementitious matrix. The embedded bars show an overall smooth initial surface. After the first accelerated corrosion, a strip of pit with significant size initiated along vertical direction of the whole steel. And then, more and more pits nucleated and grew with the increase of corrosion time. At the end of the experiment, the region near the inner

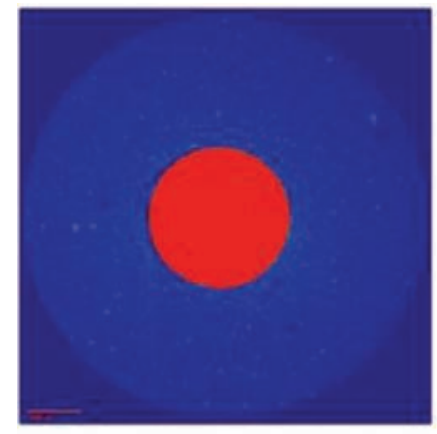

(a) Un-corrosion

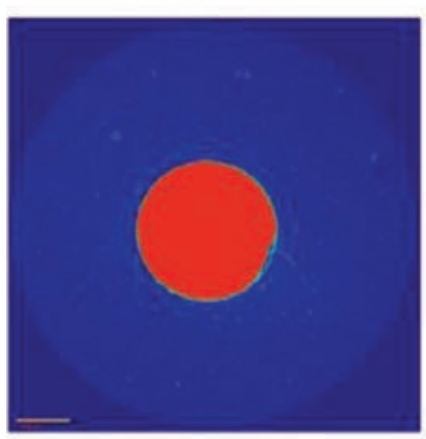

(d) Cracks formation

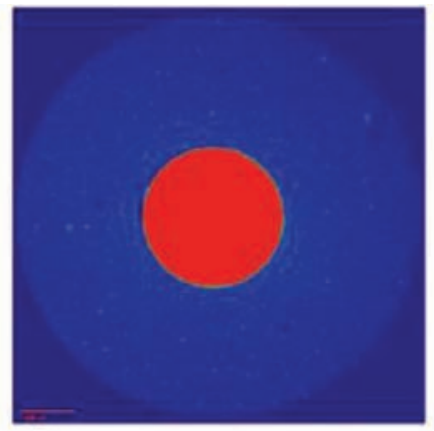

(b) Corrosion initiation

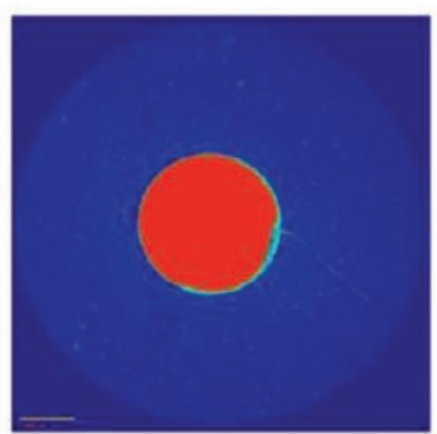

(e) Cracks propagation

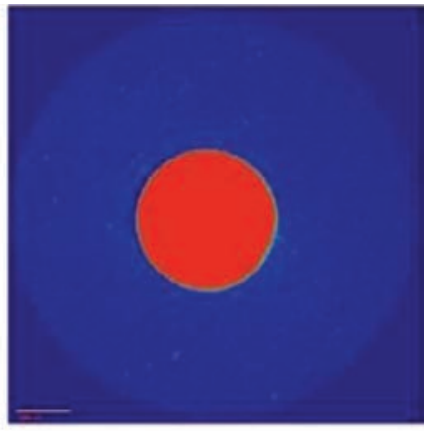

(c) Free expansion of rust

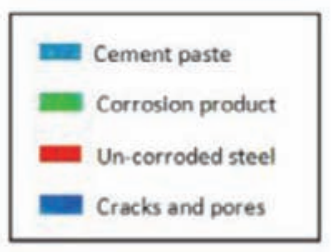

Figure 1. Reconstructed tomograms of embedded steels in different accelerated corrosion time. 


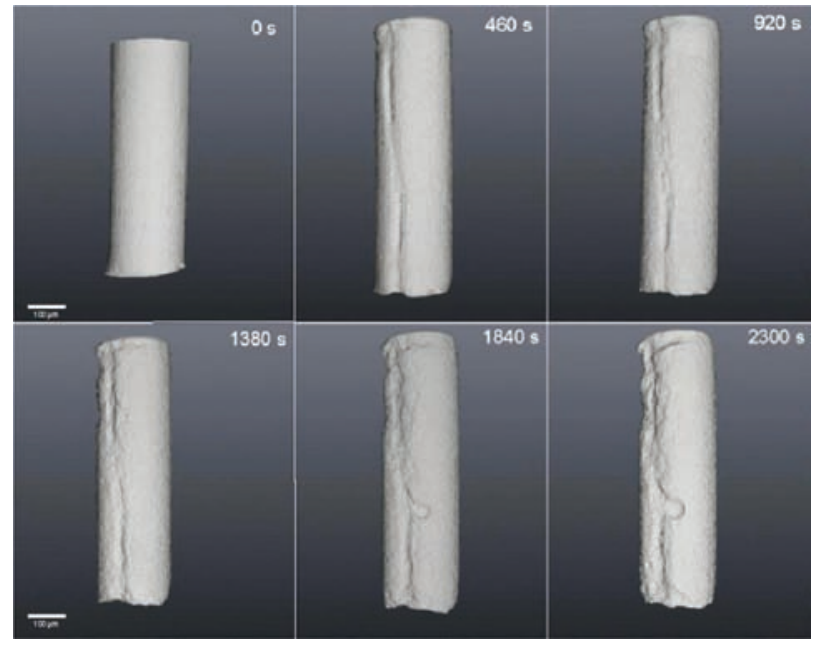

Figure 2. 3D images of surface of embedded steels in different accelerated corrosion time.

end of the cracks showed signs of severe corrosion, causing localized loss of steel, due to the strong current intensity which leads to form cracks quickly.

As shown in Table 1, the volume of embedded steel decreases steady with the increase of corrosion time. As shown in Figure 3, there is similar developing trend of corrosion ratio comparing with three different methods (Weighting method, Theoretical calculation, and XCT analysis). However, it is obvious that the corrosion ratio measured by X-ray $\mathrm{MCT}$ has better correlation with the data calculated by Faraday's law. It also indicated that the data calculated by the Faraday's law is a bit higher than the other results.
The trend continues approximately to the last accelerated corrosion (theoretical corrosion data is $25 \%$ ). Afterward the relationship inverts, i.e., the data measured by X-ray $\mathrm{mCT}$ are higher than the theoretical data. On the other hand, the corrosion ratio determined by X-ray $\mathrm{mCT}$ is a higher than the result measured by weight.

Table 1. Corrosion result measured by means of X-ray CT (spatial voxel size $=48 \mu \mathrm{m}^{3}$ ).

\begin{tabular}{cccc}
\hline $\begin{array}{c}\text { Accelerated } \\
\text { corrosion } \\
\text { time (s) }\end{array}$ & $\begin{array}{c}\text { Volume voxel } \\
\text { count }\left(\times \mathbf{1 0}^{\mathbf{7}}\right)\end{array}$ & $\begin{array}{c}\text { Label volume } \\
\left(\times \mathbf{1 0}^{9} \boldsymbol{\mu \mathbf { m } ^ { 3 } )}\right.\end{array}$ & $\begin{array}{c}\text { Corrosion } \\
\text { ratio (\%) }\end{array}$ \\
\hline 0 & 6.2726 & 3.0108 & 0 \\
460 & 5.9710 & 2.8660 & 4.81 \\
920 & 5.6861 & 2.7293 & 9.35 \\
1380 & 5.3235 & 2.5601 & 15.13 \\
1840 & 5.0488 & 2.4234 & 19.51 \\
2300 & 4.5704 & 2.1938 & 27.13 \\
\hline
\end{tabular}

After the specimens had been dismantled, the crosssection of samples is also carefully inspected by SEM and EDS (Figure 4). With the comparison of the SEM micrographs and the X-ray $\mu \mathrm{CT}$ scans, the boundaries of the pits matched completely within the limits of the method's resolution. The un-corroded area in centre of the specimen (spot 1), corrosion products surround the steel bar (spot 2), and cement paste (spot 3) are identified clearly by means of EDS. The result of SEM and EDS further verified the data measured by X-ray $\mu \mathrm{CT}$ to be reliable.

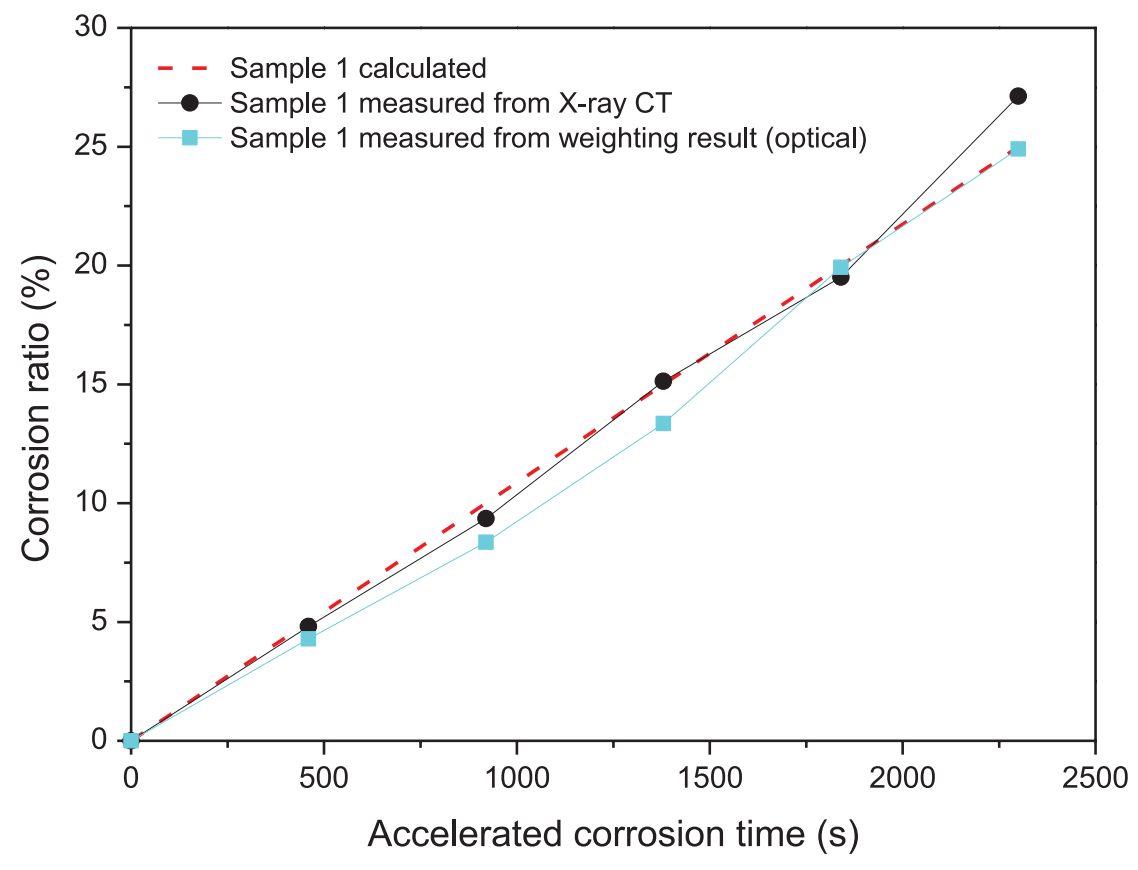

Figure 3. Comparison between the steel corrosion predicted by Faraday's law, measured by X-ray CT. 


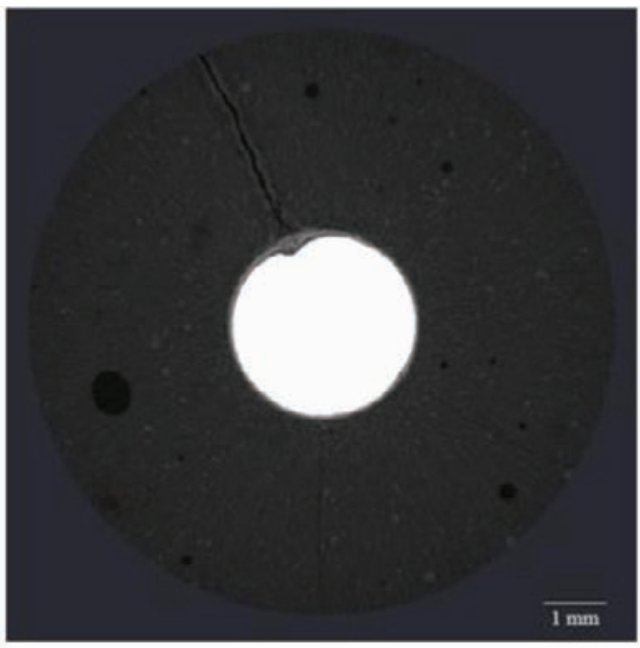

(a)

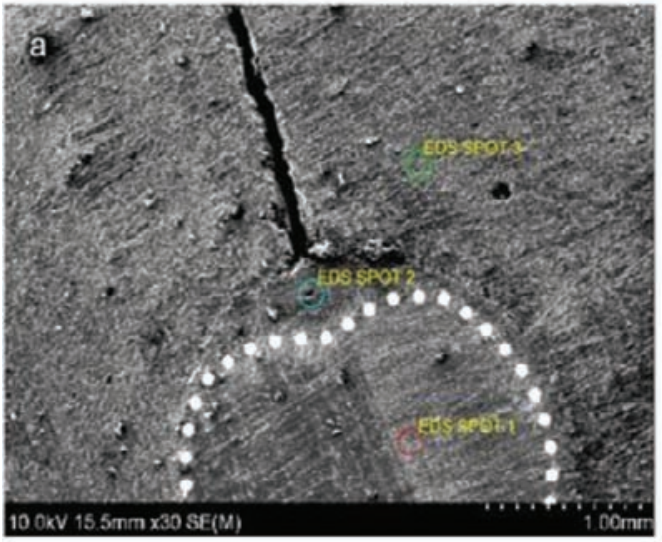

(c)

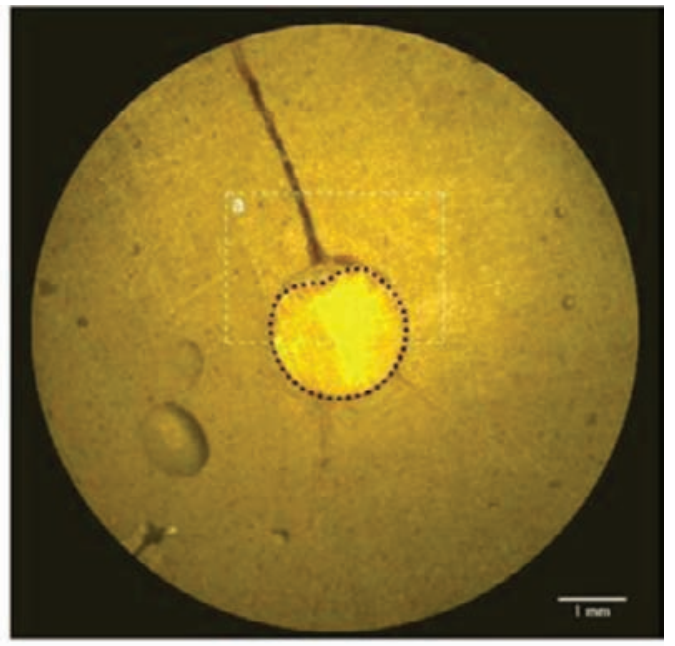

(b)

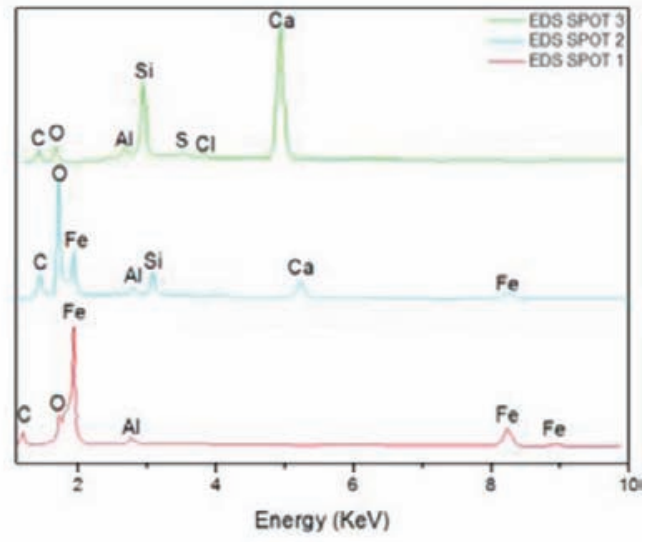

(d)

Figure 4. (a) Cross-section of Sample 1 obtained by X-ray CT scans; (b) SEM image of the cross-section of Sample 1; (c) and (d) EDS result of surface of the cross-section.

\section{CONCLUSION}

The X-ray computed microtomography (X-ray $\mu \mathrm{CT}$ ) system is successfully applied to 3D in situ and quantitatively studies the whole corrosion behavior of steel in cement paste. It is demonstrated that this testing method has a priority in cementitious material testing field. In addition, the corrosion ratio predicted by the Faraday's law is larger than the volume loss measured by the X-ray $\mu \mathrm{CT}$ experiments and gravimetric method, due to non-linear corrosion behavior of steel. But the corrosion ratio measured by X-ray $\mu \mathrm{CT}$ has better correlation with the data calculated by the Faraday's law than the results obtained by gravimetric method.

\section{REFERENCES}

Landis, E. H., \& Keane, D. T. (2010). X-ray microtomography. Materials Characterization, 61, 1305-1316.

Naik, N. N., Jupe, A. C., Stock, S. R., Wilkinson, A. P., Lee, P. L., \& Kurtis, K. E. (2006). Sulfate attack monitored by microCT and EDXRD: Influence of cement type, water-to-cement ratio, and aggregate. Cement and Concrete Research, 36, 144-159.

Sugiyama, T., Promentilla, M. A. B., Hitomi, T., \& Takeda, N. (2010). Application of synchrotron microtomography for pore structure characterization of deteriorated cementitious materials due to leaching. Cement and Concrete Research, 40, 1265-1270. 